\title{
In memoriam: Bernd Walter Scheithauer (1946-2011)
}

\section{Caterina Giannini}

Published online: 25 November 2011

(C) Springer-Verlag 2011

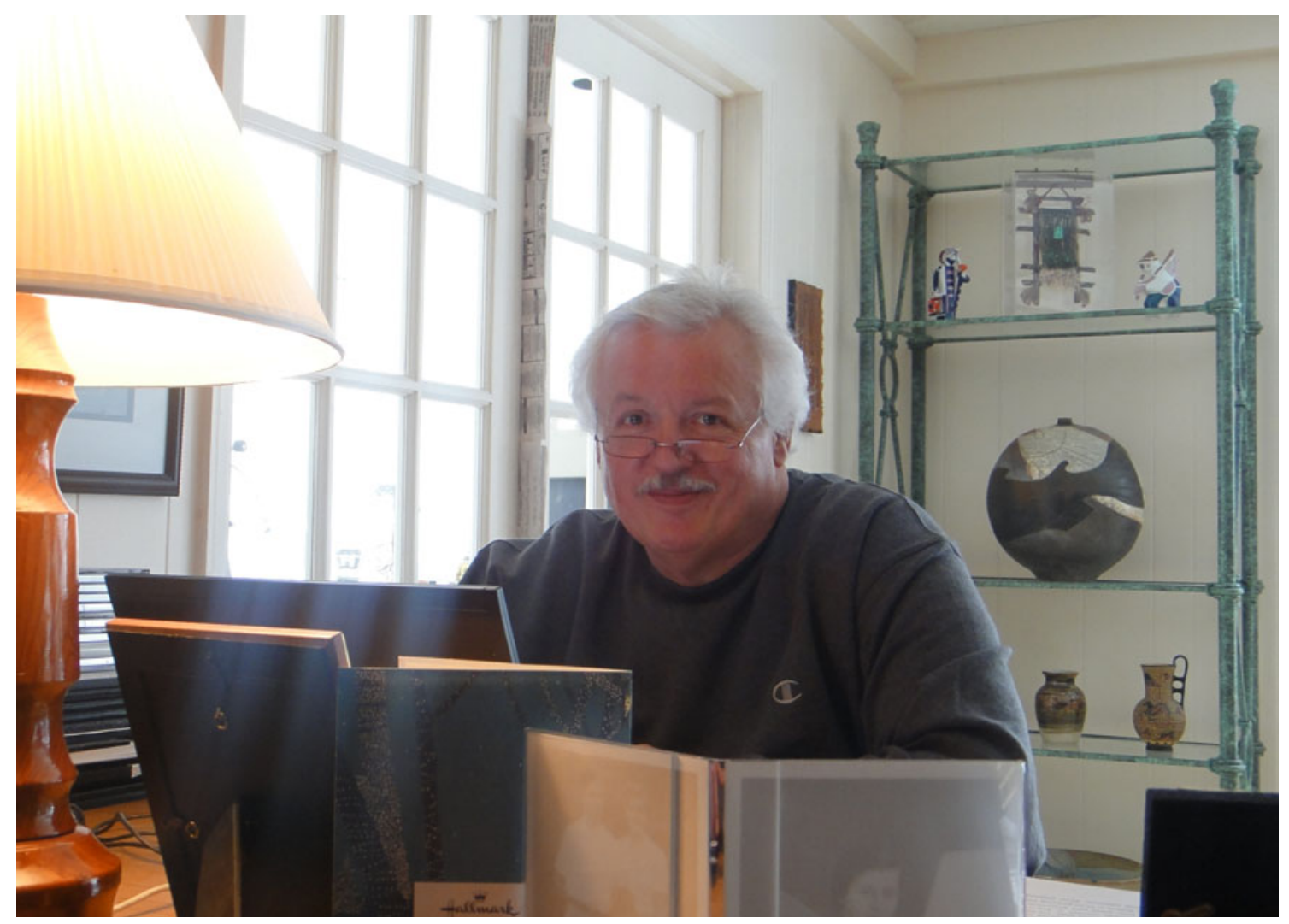

On September 19th, 2011, Professor Bernd Walter Scheithauer passed away at his home in Rochester, MN unexpectedly and prematurely. Bernd was born August 30, 1946 in Gelenau, Germany to Walter and Renate (Scholz)

C. Giannini ( $\square)$

Mayo Clinic, Rochester, MN, USA

e-mail: Giannini.Caterina@ Mayo.edu
Scheithauer. At the age of 7 , his family migrated to the United States and he grew up in Eureka, CA. He graduated from Humboldt State College in Arcata, CA and went to medical school at Loma Linda University School of Medicine in Loma Linda, CA. In 1979, after completing his Residency and Fellowship in Surgical Pathology and Neuropathology at Stanford University Medical Center, Palo Alto, CA, he left California for the Mayo Clinic in 
Rochester, MN, where he quickly raised through the academic ranks to Professor of Laboratory Medicine and Pathology and remained through his full career.

Neuropathology was for Bernd the love of his life and to some extent his work was his life. He was truly a unique surgical neuropathologist, the result of his personal inclination coupled with his life long position at Mayo, where he practiced as a surgical pathologist and neuropathologist. Since the beginning of his career he made the tumors, which were considered in some ways the "less noble" part of neuropathology, the focus of his life. He was very proud to be a "lumps \& bumps" neuropathologist and had little patience for autopsy neuropathology. He wanted to help the living.

Dr. Rubinstein, who was his teacher, more than once complained to him that he was not "a serious neuropathologist" because he was too much into diagnostics of tumors rather than science. However, in doing so, not only Bernd carried the legacy of his teacher, but also he was the one who "took things further". Dr. Rubinstein himself recognized that when he proposed Bernd as one of the editors of the Brain Tumor WHO classification in the early 1980s. Bernd was thankful to him and very proud of it.

Bernd loved to repeat a phrase from Newton: "If I have seen further it is by standing on the shoulders of giants". Despite their difficult relationship at times, Dr. Rubinstein was his giant.

Bernd was extremely curious and loved beautiful things, and so he was in his work. He loved the shore of North of California, where he would go walking finding all kind of beautiful things brought back from the ocean. Because of this, I think it particularly applies to him in his approach to neuropathology, what Newton once said about himself "he was like a boy playing on the sea-shore, and diverting himself in, now and then finding a smoother pebble or a prettier shell than ordinary, whilst the great ocean of truth lay all undiscovered before him".

Bernd was a very acute observer, always full of insights. He would brilliantly approach the most unusual and difficult cases and would systematically explore all the diagnostic possibilities, finding the support he needed by exhausting all the available techniques from the classical histochemical stains, to immunohistochemistry, to electron microscopy.

Every single case deserved a maximal effort.

Because of his curiosity and unique diagnostic approach, he was the first one to see, describe and characterize many new tumoral entities, among which dysembryoplastic neuroepithelial tumor, clear cell meningioma, chordoid glioma, rosette forming tumor of the fourth ventricle and the most recent pituitary blastoma. In many cases, the recognition of these new and peculiar entities had considerable clinical impact.
His interests spanned the spectrum of surgical neuropathology, from peripheral to central nervous system, to pituitary. Pituitary was his favorite, because "the full organ could sit on a single slide", allowing him to explore it deeply in every single detail. And it is also to the field of pituitary pathology that he has made seminal contributions together with his life long mentor, colleague and friend, Dr. Kalman Kovacs.

He loved working with people and working on projects from start to end. He loved working on papers and editing was a true passion. Most of the times, he walked with a manuscript in his hands and could edit manuscripts in the most unlikely situations.

He was extremely productive. With more than 700 peerreviewed papers, 80 book chapters and several books, among which the Surgical pathology of the nervous system and its covering, with his long-time friend Peter Burger and both the Tumors of the central and peripheral nervous system AFIP fascicles, there is no single aspect of surgical neuropathology that he had not fully explored. This incredible body of knowledge and experience is his generous gift to us and future generations and it is his legacy.

Bernd had a passion for teaching and especially teaching around the microscope. He was brilliant and entertaining. He was generous with his time and knowledge, which he made available to everyone patient enough to sit through his sign-out sessions late into the evening, and not infrequently on weekends. He taught hundreds of residents, fellows and visitors from all over the world.

He loved traveling, which together with his passion for teaching made him a tireless lecturer around the world. From his trips he would bring back cases, stories and wonderful photographs, which again he would share with us at sign-out time and at conferences.

As his scholar, I can say he was the best teacher I could have had. As my colleague, he was always there for me.

As it is true for any of us, however, Bernd was not perfect. He was proud, determined and would not take no as an answer. He was a very complex man. Finding my own way with him was at times challenging. Nonetheless I recognize that who I am today is largely because of him and for this I will always be grateful. He will always be with me.

Bernd is survived by his son, Hans and daughter, Monika, two grandsons Aiden and Finnegan Bernd Maxey and his mother, Renate, along with whom we are mourning. His memory will be cherished by all who had the privilege to be close to him.

Acknowledgments I am most grateful to Xiaoling Yan, Dr. Scheithauer's visitor from China for sharing with us Bernd's picture taken at his home desk this past winter. 